\title{
In Search of the Optimal Venture-to- Capital (V2C) Business Model
}

Tommi Rasila, (E-mail: Tommi.Rasila@tut.fi), Tampere University of Technology

\begin{abstract}
This paper illustrates the differences between traditional and emerging business models in the recently identified Venture-to-Capital (V2C) area. This area refers to the stage in the development of a company when it is "between Venture and Capital", ie. before the idea or the venture is eligible for Venture Capital investment. Many entities exist to assist companies in the V2C operating space. Most obvious taxonomy of the V2C players includes Incubators, Advisors, Business Angels and Classic/Seed VC. All these have different business models, including motive, contribution, incentive and revenue model. There is, however, a large number of new operatives in this field which do not quite fit this traditional taxonomy.

In this study, a number of these new operatives are examined and their business models outlined. When comparing the traditional and new business models, three observations are made as conclusions: New models are hybrids of traditional models with only some new features; Contributing intellectual capital in the sense of "sweat capital" or business knowledge is seen as a key requisite; Trend goes towards obtaining equity interest in the target company for upside potential in the compensation. This study paves way to future research in creating new taxonomy for Venture-to-Capital operatives and delineating a "best practice" to the practitioners in the field.
\end{abstract}

\section{Keywords}

Venture-to-Capital, V2C, Venture Capital, Informal Venture Capital, Incubator, Business Angel, NTBF

\section{Introduction}

The importance of small and growing enterprises in creation of jobs, innovations and wealth is unquestionable. Studies about New Technology-Based Firms (NTBF) and Venture Capital show that both the supply of good start-up companies and supply of capital to fund these ventures is vital to success. Still, despite the general availability of funding and several principal models for aiding fledgling companies, many promising ventures fail to make it and sink into oblivion before crossing the hurdle to success.

Over the years, scarcity of seed funding and existence of capital gap have become a major obstacle in growth of start-up companies. Venture capital as an industry has traveled far from the original classic VC model born in the 50's, as Bygrave and Timmons noted in their landmark book "Venture Capital at the Crossroads" (1992). At the same time, venture capitalists would need more ventures to soak the capital from their funds profitably. This mismatch inevitably has impact on national economies if not dealt with. Something can be done, and indeed, in a free economy it is evident that new business models will arise, if existing ones are not operating perfectly.

Nevertheless, the key problem is that many promising companies fail to get investment, even though they seemingly have got all the parts needed of success. Is there something wrong? There are various reasons for this, and of course, not all companies are fit for success in the first place. But if we define that receiving venture capital funding (so-called "first round") would be a measure for success, we can reflect the challenge facing these new, usually fast-growing companies against the investment criteria of VC companies. 


\section{Venture-To-Capital (V2C) in Brief}

First of all, we call the area starting from birth of the company and ending to the point when it arrives to the operating environment of VC companies the Venture-to-Capital (V2C) area. Secondly, our hypothesis is that this $\mathrm{V} 2 \mathrm{C}$ area works deficiently like any market which is in development. Therefore, the assumption is that the current operating models can be developed further, thus improving target start-up's chances for success.

When looking at work of Mason and Harrison, we see that a given company has to possess certain qualities to be "investment-ready": It has to have suitable organization structure, be willing to grow, be prepared to give out certain amount of ownership and control in exchange for the investment, and so on. In practice, this means that the company has intrinsically prepared itself for being able to absorb the investment and use it for growth (Mason and Harrison, 2000, 2001 and 2002). Much in the same manner, venture capitalists have their requirements, checklists, and other investment criteria to assist them in screening their prospective target companies. In V2C context, when a company fulfills these investment criteria it becomes "investable".

Similarly, a V2C operative has its set of criteria for screening of "viable" or "promising" companies. In $\mathrm{V} 2 \mathrm{C}$ context, when a company is of interest to the $\mathrm{V} 2 \mathrm{C}$ it is called "prospective" venture. Implicitly, this definition also carries the notion that a prospective company has potential to become of interest to the venture capital market. In other words, a prospective venture possesses potential to become investable.

When a given company has reached the status of being investable, the suggested model assumes that it will eventually receive investment ${ }^{1}$. As the VC enters the company as an owner, it is assumed from the principles of venture capital finance that he brings along many functions needed to develop the company further (see eg. Seppä, 2000). The ultimate goal for the VC is exit, for which the company has to reach "listable" status. The term refers to public listing of the company, realized by an IPO, but we must not look at the case so narrow-mindedly since most exits happen through trade sale. Nevertheless, the requirements for a listable company fulfill the needs for both IPO and trade sale, and it is a task of the venture capitalist to guide the company to this stage.

After the exit the company either is public (in the case of an IPO) or ceases to exist as a legal entity it was (in the case of an acquisition). Thus, if the company exists, it is "public". This operating mode was preceded by "VC mode" and "V2C mode", when the venture was being assisted and backed by either V2C or VC operative. Before this, the venture was alone, playing "solo", although we have to note that the division is not always this clear-cut: V2C players may be present to certain extent also in the initiating phases of a company, and still continue their work during the VC phase. VC's may also work outside their own arena, helping companies to become investable and being involved in recently listed companies.

These statuses and respective modus operandi of a company can be illustrated in parallel of stages in a company development. The most common classification includes stages like idea, pre-seed, start-up, early growth, fast growth and maturity. Between each stage, the status to be reached represents a set of rules to be met, before the venture can advance to the next stage. For instance, rules and requirements of becoming investable have to be met, before the company can advance from start-up phase to growth phase, moving from V2C operating mode to VC operating mode. All four aspects - status, operating mode, development stage and barriers - are put together in the accompanying picture.

\footnotetext{
${ }^{1}$ Naturally, there are other alternatives - deciding to do without the investment, getting acquired and so on - but as these are not in the scope of this paper we will concentrate on our simplified model.
} 


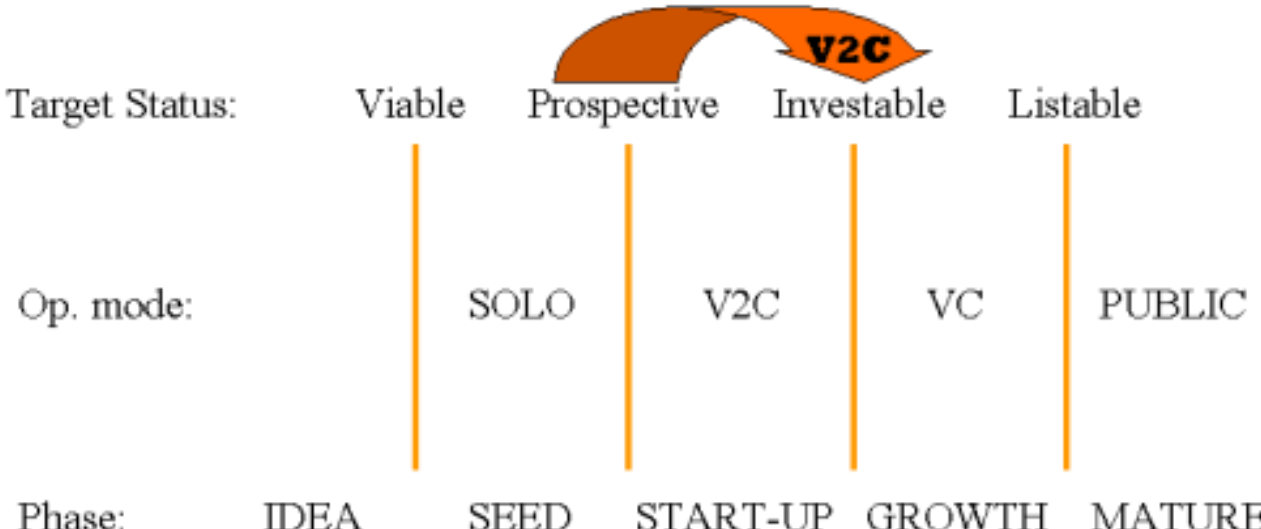

Figure 1. V2C Target Statuses and Phases of Company Development (adapted from Jungman et al 2002)

The purpose of this paper is first to briefly explain the key elements in operating models of the existing V2C operatives: Incubator, Business Angel, Advisor and Seed Capital VC, operating according to the so-called Classic VC model. After this, a variety of new operating models will be presented: eAccelerator, which is an elaborated model of traditional incubator; Source Code Finland, which resembles seed VC without using money; Virtual CEO, which - being a business angel without money - is almost an archetypical V2C operative; LINC Trial Marriage, which brought new incentives to Business Angels; and Venture Stables, which is a modest corporate venturing activity within a Tampere University of Technology.

\section{Traditional V2C Business Models}

In this chapter, we analyze the four existing categories of V2C players - Incubator, Business Angel, Advisor and Seed Capital VC - as we outline their business models. These four different operatives are not directly comparable, as their objectives are different. In many cases they complement each other in the field, instead of competing rigorously. In a way this is understandable and positive, since the newly-hatched companies might often be too weak to withstand its aides to compete against each other.

The four categories are not an all-inclusive and complete taxonomy. This can be seen from variations inside each category as well as new emerging variations, some of which are presented in the next chapter. Nevertheless, in order to extend our understanding on future of $\mathrm{V} 2 \mathrm{C}$ business models, we must first look at what we have had in this area for the past years.

\section{Business Angel}

Basically, a business angel is an individual (in contrast of a legal entity) with certain amount of personal wealth and business skills, and willingness to contribute some of these to embryonic companies. The wealth may come from many sources, ranging from own earlier successful entrepreneurship to having inherited a fortune. Due to differences among this group, there are taxonomies differentiating business angels in groups based on variables such as activity, available capital, average investment and focus group (Coveney \& Moore 1998, Eriksson and Sørheim 2002, Gaston 1989, Sørheim \& Landström 2001).

Accordingly, the amount of capital available to be invested as well as the business skills vary greatly; a successful executive may be willing to invest some of his hard-earned money to get more challenge to his life, bringing in most favourable case invaluable expertise to the company in his person. On the other hand, a well-off exentrepreneur may wish to invest some of the capital earned in the IPO of his company to assist other companies in their early stages. For this business angel, investments may be like bets, but his presence may still provide the company with much more than just money: Prestige, networks and credibility, to name a few examples. 
Nevertheless, the business model of a business angel is quite simple: They invest money in early stage ventures, and in return they receive an equity stake, hoping to get their investment back with profit. Besides the "normative $\mathrm{VC}$ exit routes", being trade sale and public listing, the profit scenario of a business angel includes also other alternatives, such as sellback to the entrepreneur, selling forward to other investors or keeping the stake and collecting dividends. Thus, the investment time span of an angel is relatively long.

To accomplish this goal, a typical business angel is willing to contribute some of his time to the company as well. This work tends to be non-operative, such as board work or screening for potential VC investors, but operative work is by no means exceptional: interacting or even being a member of the management team, assisting in marketing planning and implementation of the plan, lobbying for clients through own networks and so on. Only in rare cases is the angel paid for these services. The caveat is that it is not easy for the entrepreneur to know the value and quality of these services in beforehand. In other words: it is not easy to judge the quality of the business angel when looking at the investment proposal.

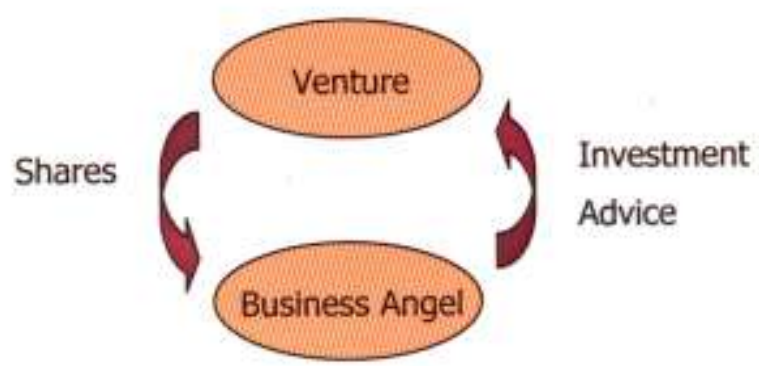

Figure 2. Business Model of a Business Angel

Simplified business model of a business angel can be seen in the above picture: In return for the equity stake given to the angel, the company receives capital investment and in most cases certain amount of advice and work, either consultative, operative or board work. As the angel is an individual, form of operation is informal and in a sense "unorganised". Still, the commitment level is high and time span long due to the vested interest.

\section{Classic/Seed VC}

Classical VC model is the most traditional model of venture capital investment. Currently, the private equity market has shifted away from this model towards more capital-intensive later-stage investments, but it can be considered that the seed VC companies still operate according to this model. Also corporate venturing works this way in a sense; typically large and mid-size corporations have their funds for spinning off internally born business ideas, which do not quite fit their own core business but are still too valuable to be left unexploited.

Typical attributes in this model include long investment span, high upside potential and risk, immaturity of target company requiring lots of attention from the investor and relatively small amount of equity required. These factors - risk, attention, small investment size - bring in the effects of capital and skill gaps, repelling many mainstream VC players off the early stage companies (Rasila et al, 2002). Nevertheless, entering the target as early as possible should still bring most lucrative results in exit phase. 


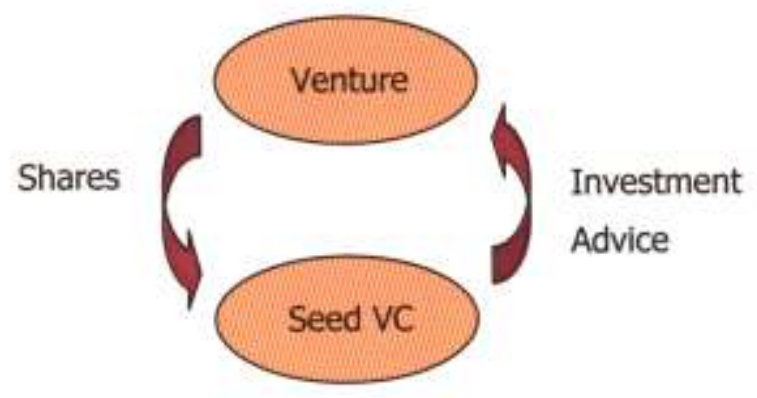

Figure 3. Classical Seed Venture Capital Business Model

The business model resembles the one of a business angel in many ways, but in this case the operative is a legal entity, being professional in the activity in question. Also the type of networks and advice brought in may be substantially different. Networks may be more formal and defined, and be international. Advice is in most cases limited to board work and assistance in special situations such as recruiting top executives, raising capital and crisis management.

\section{Incubator}

Principally, an incubator is an "office hotel" for fledgling companies. Office services are readily available and a variety of business development and support services are at hand easily. Apart from some government grants or subsidies for rent, incubators do not finance their tenants, but merely offer their services and office space for money. Thus, incubator as a concept is fairly straightforward, but in reality its incarnations come in many forms.

As Aernoudt defines it "a business incubator's main goal is to produce successful firms that will leave the incubator financially viable and free-standing within a reasonable delay". Yet, the same author presents a taxonomy with five different main categories of incubators, including technology incubators for overcoming entrepreneurial gap and regional development incubators, which are in most cases political operations, trying to create businesses and jobs in areas which are underdeveloped or undergoing a structural change. Furthermore, the operation may be either real or virtual incubator. All in all, it can be concluded that incubator is an umbrella concept (Aernoudt 2002).

Incubators themselves may be non-profit or for-profit organizations, but as pointed out by Paul A. Gompers in his recent lecture to US venture capitalists, most of the hundreds of for-profit incubators established in the US between 1999 and 2000 have had to close their doors. Reasons for this were seen to be limited experience of managers, too ambitious investment plans and adverse selection of companies, as the incubators only got the see the "bad deals".

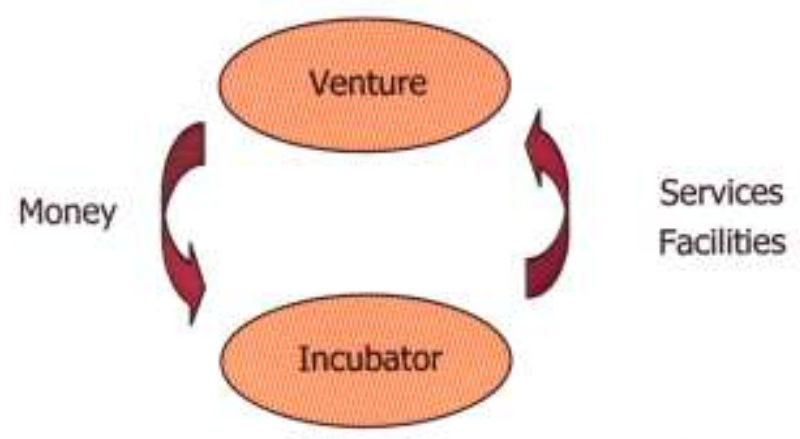

Figure 4. Business Model of an Incubator 
The incubator business model shows that services and facilities are given to the company for money. In some cases, some part of the services are offered for free or subsidized with governmental support. Financing is a key issue for many of the tenants, as the funding has to come from business angels and other seed financiers. Therefore, networking with these parties is crucial for the long-term success of incubator.

Overall, the time span of an incubator is medium-range and the organization is a legal entity. This gives possibility to building a good organization to support the ventures. Unfortunately in many cases the executives of the incubator do not have lots of business development skills. Furthermore, as there is no vested interest, ie. long-term incentive such as equity stake neither for the executive or the incubator itself they may also lack commitment to the long-term success of the company.

\section{Advisor}

Advisors may be individual consultants or consultant companies. They offer various services for money: market research, exporting, writing business plan, raising capital to name but a few. They are generally professional and entrepreneurial in what they do, delivering good quality advice for different situations. Naturally, actual results may vary as not all advisors are equal, and none of them is an expert in every issue facing a start-up venture.

Like incubators, they provide no funding but on the contrary require immediate monetary compensation for their services. Therefore, unless the target venture is backed up with excessive amount of "friendly money", it has to find a source for financing. This, of course, can happen through an advisor offering this kind of services. Networks are crucial for the long-term success of an advisor, as they are often called in by other V2C players and vice versa.

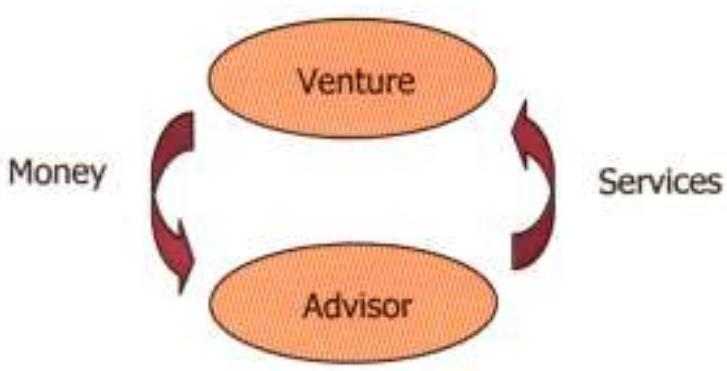

Figure 5. Business Model of an Advisor

In general, the advisor provides the client with advice on a specific issue for money. Concentrating on one area of development, the approach is seldom holistic. Also, the work is short-term by nature, as it is usually projectbased. Board work would give the advisor certain amount of long-term commitment and holistic view, but advisors are rarely seen in the board of their client companies. All in al, an advisor is a professional working with a client, not an owner looking after his possession.

\section{Summary of Traditional V2C Business Models}

There is a multitude of parameters we could use to compare the operatives presented above: means of compensation, degree of long-term commitment, availability and reachability, level of networking, scope of work, quality of skills and so on. Let us summarize some of these parameters to a table as done below: 
Table 1: Brief Summary of Traditional V2C Operatives

\begin{tabular}{|c|c|c|c|c|}
\hline & Compensation & Organization & Working model & Time span \\
\hline Incubator & Money & Professional & Bureaucratic & Medium \\
\hline Advisor & Money & Professional & Entrepreneurial & Short \\
\hline Business Angel & Equity & Hobbyist & Entrepreneurial & Long \\
\hline Seed VC & Equity & Professional & Bureaucratic & Long \\
\hline
\end{tabular}

From financing point-of-view, there are two completely opposing pairs within these four: business angel and seed VC, who bring money in, and incubator and advisor, who take it out. These pairs also differ in availability: incubators and advisors are more generally available, where as business angels tend to keep out of sight, and both them and seed venture capitalists are a scarce resource to begin with.

Before making any deeper observations, let us look at the new, emerging models, some of which are close to existing ones while some of them are not.

\section{Emerging V2C Business Models}

Someone has said: "The only stable and constant thing in the world is change". So, how have the V2C players changed, or what kind of change is required from them to adjust to the changes happening around them, in their operating environment? We could approach this question by looking at the changes already happened: the operating models of new kind of V2C players.

In our Darwinian world, time will tell which one or ones of traditional and new models are the winning ones. New variations may pick features from several other models, adding something new, and try the combination out in the marketplace. In time, this acid test will show if the model is fit for life or not: if it serves the venture and economy in general, it is bound to succeed and have followers. This, of course, assumes a perfect world, competition and economy, but it is the best we can do.

In the following, five quite heterogeneous examples of these new operatives are presented. The selection of examples is based on the effort to make this presentation interesting and thought-provoking. As these five examples can hardly be a basis for a taxonomy, a more ambitious "collection of specimen" is underway. Anyway, let us now look at these five new operatives:

- eAccelerator, boosting fledgling companies with money and advisors

- Source Code Finland, investing "sweat capital" for equity compensation

- Virtual CEO, a business angel who does not invest money but time

- Trial Marriage of LINC Scotland business angel network, overcoming the constraints of the informal VC market

- University Venture Stables, giving innovations a free push within the university

\section{eAccelerator}

eAccelerator is one of the six programs of eTampere, which is an umbrella project promoting e-business, esociety and new economy in many forms in Tampere region in Finland. The heart of the region is the second biggest city in Finland, where brick-and-mortar industries have traditionally been dominant. The transformation to new economic basis has been quite successful, though, compensating to large extent the loss of jobs in heavy industries, textile mills and shoe factories.

The city has been actively involved in many actions and organizations supporting this positive development, and one the most recent initiatives is eAccelerator. It is operated by a leading business development agency in 
Tampere region, Hermia Business Development, which has been working closely together with the Hermia Science Park and adjacent Tampere University of Technology.

Companies are screened in normal manner with public funding, but also by use of a business plan competition, trying to promote entrepreneurship. Contracts with accepted companies are tailored from case to case, with variable time span, deliverables and compensation method. In addition to various business development services by Hermia Business Development, ranging from patent consulting and market research to improving the business plan and raising capital, the deliverables may include certain amount of investment. The investment is not intended to cover operative costs such as marketing or product development, and is too small for these activities in the first place anyway. Instead, it is to be used to cover up direct costs of the business development project such as use of other experts or patenting, according to the guidelines agreed in the contract in beforehand.

Method of compensation is preferably money, but success fee or equity can be used as well. Payback is not immediate, but triggered by set milestones, such as VC funding or major sales deals. Payback may also be conditional, which brings more risk and incentive to the scheme. So far (November 2002) more than ten companies have been accepted to the fairly active program, and the results have been promising.

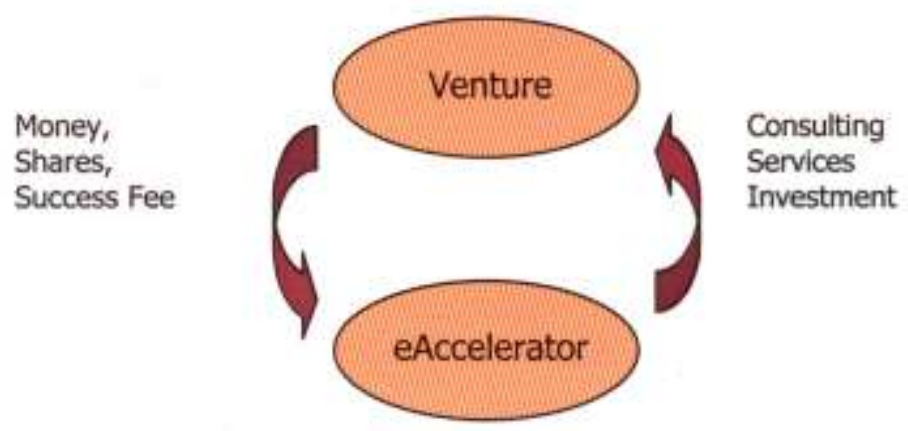

Figure 6. Model of eAccelerator

eAccelerator business model is a mixture of business angel, advisor and seed VC, which is natural since its operation has features from all of these players as well. Business angel would give more money and only accept shares in return. Investment of a seed VC would be much less consulting-intensive and concentrate on the capital injection instead, while advisor might give the same amount of consulting but not accept conditional or equity payback. Depending on the assignment, time span may range from short to long. It tends to be in the longer end and definitely is if there is vested interest in the form of equity, success fee being usually a medium range incentive.

\section{Source Code Finland}

Source Code Finland resembles eAccelerator in many ways: It has a professional organization and fairly fixed time span, making work-intensive investments to existing companies. On the other hand, it explicitly prefers equity to monetary payment as compensation for the services. Also, they only invest their own time, "sweat capital" as quoted by their executive in an interview, and do not provide any capital for paying services of other advisors. So far (November 2002) they have screened 105 companies but not made an "investment" yet - therefore the success of the model is yet to be seen. 


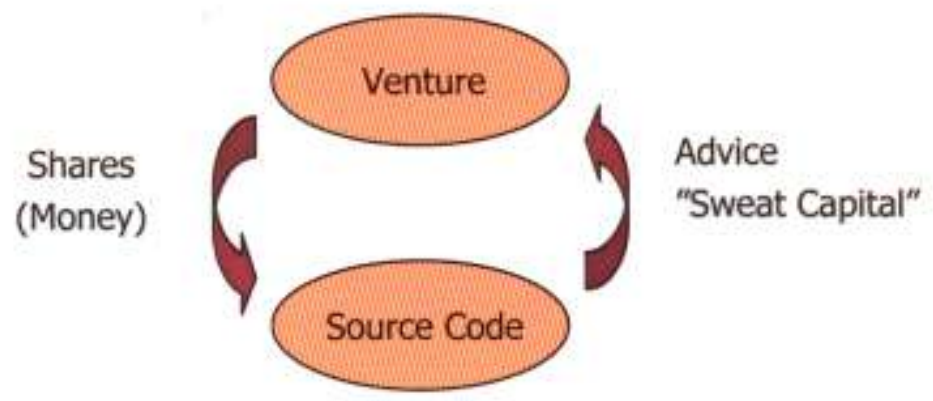

Figure 7. Business Model of Source Code Finland

The business model of Source Code Finland is fairly similar with the one of business angel, but unlike in the case with an angel there is no capital investment towards the company. Instead, one of the defined functions of this $\mathrm{V} 2 \mathrm{C}$ player is to guide the target venture to venture capital round one, and presumably exit at round two or later, adding value to the company at each phase. Time span is planned to be in the range of two years from entry to exit, which can be considered fairly long term interest. And after all, there is vested interest in the form of shares, which only bring profit to the V2C player is the venture is successful.

\section{Virtual CEO}

The Virtual CEO is a rather "unofficial" and informal concept presented by Randy Komisar, when he describes his own work in semi-fictional autobiography "The Monk and the Riddle" (Komisar 2001). Yet, as there are other individuals working according to the same model ${ }^{2}$, it deserves a place in our analysis for V2C taxonomy.

To put it simply, Virtual CEO is a business angel without money. He possesses such skills and networks, that the entrepreneur or founders of a new venture are willing to give him a stake in the company, knowing that he in turn will contribute his time and knowledge for developing the company. Upside potential gives incentive to the Virtual CEO, and it is easy to imagine that this is a win-win game.

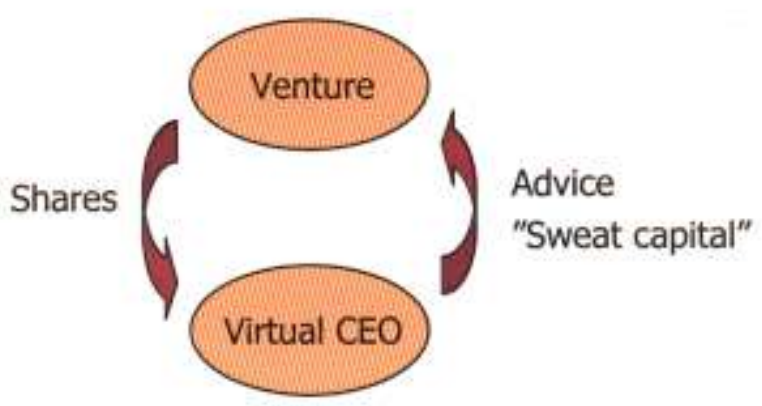

Figure 8. Business Model of Virtual CEO

The business model looks very much like the one of a business angel, except that money has been removed from the equation. We also get this model by replacing "money" with "shares" in the advisor model. And finally, we should note that the model is exactly the same as the Source Code Finland model presented above, just that in this case we are dealing with a private individual, not a legal entity.

\footnotetext{
${ }^{2}$ Including the first author of this paper.
} 


\section{Trial Marriage}

It is by now clear that when talking about the mismatch between early-stage ventures and early-stage financiers, we must look at the problem from both ends. It is true that the supply side in the (informal) venture capital market has problems, having shifted to later stage companies and sometimes posing unrealistic expectations to entrepreneurs with little to give back other than money. On the other hand, the demand side is not perfect either; new ventures are far from being ready for investment, and the screening process takes time from the potential investors especially when the target is still unorganised, working ad hoc day to day.

To intrigue business angels in exploring ventures, which seem to be interesting but need work, the Trial Marriage program was created. The program was partially funded European Union and operated by LINC Scotland, one of the eldest and most active business angel networks in the UK. Quite simply, the idea of the program was to make the angel work for the company as a consultant for up to 15 days, after which he could then make the investment decision. If the decision would be positive, support would be paid back to the program. In case of negative decision, the company would have enjoyed for 15 days of subsidized consulting (Mason and Harrison, 2002).

The program was active in 1998-99 and is being re-launched at the time or writing of this paper. Most substantial differences are that a slightly raised amount of support is paid to the company instead of an investor, and that in case of an angel investment the grant can be converted to equity, giving upside potential to the income. This is seen by LINC Scotland as an important alternative for funding the program, which is initially heavily dependent on public funding.

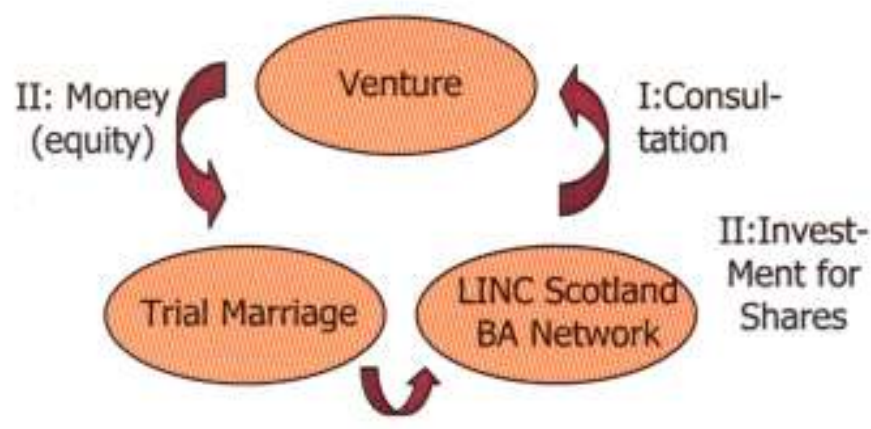

\section{I: Money}

Figure 9. Business Model of Trial Marriage of LINC Scotland

In this business model we have three parties and two phases. First, when a suitable candidate is found and accepted to the program, a business angel starts working with the company, using up to 15 days of time to inspect and evaluate the venture, and consulting the entrepreneur and resolving open issues in due course. For this work, the angel - or angel syndicate for that matter - receives money, which would be too low for a professional consultant but is enough for the angel, for whom this is not the source of daily income but more of general interest. The second phase is conditional: If a positive investment decision is made, the grant is returned to the program.

The model is fairly cost-effective, especially when we note that five of six target companies eventually got invested in. Thus, most of the money was returned back to the program. The organization of the Trial Program could be described to be non-professional yet bureaucratic, due to the involvement of many parties and European Union funding. Finally, when time span is considered, the program itself is short-term activity, but the work has potential for long-term effect as business angels get involved with and committed to the target ventures. 


\section{Venture Stables}

Like corporations foster the ideas born within their organizations through corporate venturing, some universities have established means to promote the innovations brought up by their students or staff members. This is appreciable activity with lots of potential. After all, there are many innovations in universities but the lack of entrepreneurial spirit may hinder exploiting them in practice. Supporting ideas and entrepreneurship also contributes to the job satisfaction of the staff.

One example of "University Venturing" can be found in Tampere University of Technology, which has a program called Yritystallit or "Venture Stables". When students or staff of the university have a business idea or an innovation, they can apply for the program. If accepted, university will give premises, computers and phone first for one year, with an option for second year if the venture seems to be making progress. Additionally, since especially students might be unwilling to part from the scarce amount of money intended to be used for living while studying, the university will cover up to $€ 7000$ of expenses in expert services, such as market research, patenting costs etc. The stable also takes advantage of the more traditional innovation and patenting service present at the university.

Venture Stables is in a sense a "virtual organization", as the premises are not all in the same place but usually assigned at the faculty where the idea originates in order to help the daily work of the embryonic entrepreneurs. Furthermore, there is no full-time staff, as managing the screening process and supporting the ventures is outsourced to a business development company working closely with the university.

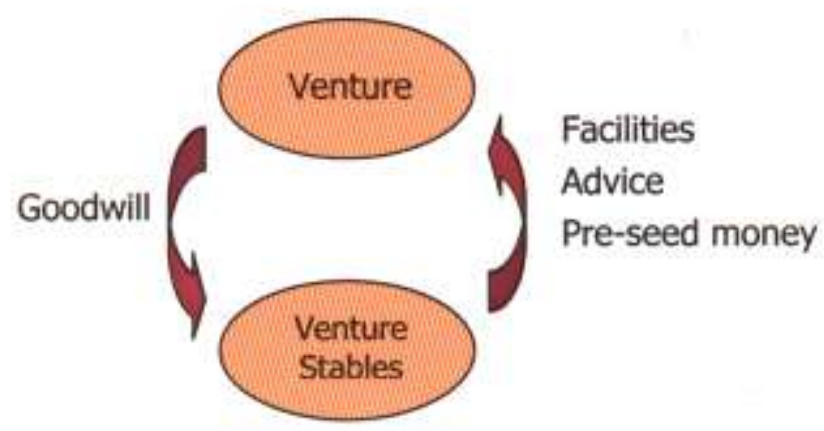

Figure 10. Business Model of Venture Stables of Tampere University of Technology

The operating model has something in common with incubator, advisor and seed VC, yet the profit model seems to come straight from the Red Cross: the venture stables expect no money back from the venture nor are they requesting and equity stake in it. Not that the university would be capable to accept shares in compensation of money or services for that matter - local legislation prohibits this. For this reason, the activity could be described as "strategic charity work", with internal job satisfaction, welfare of the society and goodwill in general as ultimate goals. The organization is practically non-existent and the time span is mid-range.

\section{Summary of Emerging V2C Business Models}

Again, we summarize some of the key features of the V2C operatives in a table below. Apart from the nonprofit Venture Stables, compensation method seems to be falling more and more on the equity side, and time span is long. It could be argued, that professional organizations such as Source Code Finland and eAccelerator are not bureaucratic but entrepreneurial, based on their success-based incentives. 
Table 2: Brief Summary of New and EmergingV2C Operatives

\begin{tabular}{|c|c|c|c|c|}
\hline & Compensation & Organization & Working model & Time span \\
\hline Source Code F. & Equity & Professional & Bureaucratic (?) & Long \\
\hline eAccelerator & Money/Equity & Professional & Bureaucratic (?) & Long \\
\hline Virtual CEO & Equity & Hobbyist & Entrepreneurial & Long \\
\hline Trial Marriage & Money/Equity & Hobbyist & Bureaucratic & Short>Long \\
\hline Venture Stables & Goodwill & Professional & Bureaucratic & Medium \\
\hline
\end{tabular}

Let us no go forward to comparing all presented models together and trying to analyze our findings so far. Based on these findings, an effort will be made to tentatively outline a "best practice", as it is still too early to speak about delineating any normative $\mathrm{V} 2 \mathrm{C}$ player in this context.

\section{Discussion and conclusions}

In this study, four traditional and five new operatives were examined and their business models outlined. In this chapter, these business models are analyzed and their strategy logic summarized, trying to build understanding of system logic of $\mathrm{V} 2 \mathrm{C}$ area. An effort will then be made to sketch the "best practice" operating model of a new kind of $\mathrm{V} 2 \mathrm{C}$ operative.

When comparing the traditional and new business models, four observations are made as conclusions. First of all, new models are hybrids of traditional models with some new features being tried out in each case. Being a business angel without money or making non-profit corporate venturing inside a university is a new variation of an old scheme, and time will tell if the variation is successful. If it is, it will stay and have followers, like any other business found profitable. What are the sustainable key success factors is the question.

Secondly, contributing intellectual capital in the sense of "sweat capital" or business knowledge is seen as a key requisite. Current venture capital industry has enough funds to give it to those in need, but has shifted away from the early stage companies in both minimum size of investment as well as expertise. This is among others due to the fact that venture capital activity is not scalable, when more money is poured in, the number of VC partners and their combined expertise should grow accordingly. This has not happened, thus creating a need for the V2C industry to step in to fill the skill - or competence - gap.

Furthermore, to make the V2C work as efficient as possible, there should be possibility for an optimal V2C player to invest also money. Otherwise, the financial difficulties and raising capital will hinder the development speed, which in many cases is crucial. This could be imagined to be own money or a fund managed by the player, or even "outsourced" to a sturdy network of business angels, even though partnership-like fund as with most VC funds would be most flexible and therefore most viable option.

Finally, it can be seen that the trend goes towards obtaining equity interest in the target company. This has several advantages. First, new venture has many shares to give, but no money with which to pay. Second, the upside potential is highly motivating to the V2C party - at least as long as the venture looks promising. Third, sharing ownership spells long range commitment to both parties in question. Naturally, like all coins this has two faces, too: Being paid in equity introduces need for operating capital and major business risk to the V2C player. And in the case of a successful exit, it is the most expensive way of payment for the entrepreneur - who in the end of the day may still be on the receiving side of it.

The following table summarizes the key parameters of $\mathrm{V} 2 \mathrm{C}$ business models. It combines the two tables presented before, adding a hypothetical $\mathrm{V} 2 \mathrm{C}$ player in the end of the list presented. The parameters of this "best practice" V2C player are discussed in the following. 
Table 3: Summary of Traditional and Emerging V2C Operatives

\begin{tabular}{|c|c|c|c|c|}
\hline & Compensation & Organization & Working model & Time span \\
\hline Incubator & Money & Professional & Bureaucratic & Medium \\
\hline Advisor & Money & Professional & Entrepreneurial & Short \\
\hline Business Angel & Equity & Hobbyist & Entrepreneurial & Long \\
\hline Seed VC & Equity & Professional & Bureaucratic & Long \\
\hline Source Code F. & Equity & Professional & Bureaucratic & Long \\
\hline eAccelerator & Money/Equity & Professional & Bureaucratic & Long \\
\hline Virtual CEO & Equity & Hobbyist & Entrepreneurial & Long \\
\hline Trial Marriage & Equity & Hobbyist & Bureaucratic & Short \\
\hline Venture Stables & Goodwill & Professional & Bureaucratic & Medium \\
\hline "V2C Operative" & Equity & Professional & Entrepreneurial & Long \\
\hline
\end{tabular}

Probably the most crucial notions from the point of the target venture are the quality and level of services given, and true long-term commitment to the development and success of the investee company. These requirements speak first of all for a professional organization, developed over time of seasoned, committed experts. Additionally, the requirement of long-term commitment to success of target ventures strongly suggests, that there has to be vested interest in the company. This commitment can be realized in form of success fees, but the most intriguing alternative for all parties is equity, bringing longest and strongest ties as well as highest upside potential. Furthermore, equity incentive should preferably be extended to the individual executives of the $\mathrm{V} 2 \mathrm{C}$ player to promote entrepreneurial attitude to the business development done in the target companies. The V2C player could also be a partnership like $\mathrm{VC}$ partnerships of today, with part of the success flowing back to the partners doing the actual work.

As noted earlier, the optimal V2C player has capacity to invest seed capital to the target venture. Looking at the current de facto business model of a venture capital partnership we find a model which can be used as an example. The fund should be big enough to avoid parsimony, but also allow small investments with long time span and high risk. Even if this resulted in risk of unsuccessful investments, the approach might do better than screening the companies too tightly, rejecting most proposals and then giving even the most promising companies just peanuts, asking them to "prove their business case" with an investment too small to begin with. Nevertheless, it goes without saying that even if the funds came from government, like in the early days of European VC, the managing partnership should have control over the fund to avoid bureaucracy and to genuinely take responsibility of its profitability.

In addition to the investment fund, the optimal V2C company should have ample amount of dedicated experts at its disposal. Own staff being very expensive this would preferably be a network of experts, or maybe even a Knowledge Fund "'raised" for this purpose (Seppä 2002). This "brains portfolio" could be created for a set time and managed somewhat in the same manner as financial funds. People would enroll to be limited partners and then be assigned to work for suitable companies where their contribution would be most useful. Thus, our assumption is that there would be professionals from universities, executives from corporations and retired entrepreneurs who would give their time and wisdom and act as board members or advisors for equity compensation. These people may be reluctant to leave their positions for entrepreneurship; this could bring them closer to small companies, resulting in "part-time entrepreneurship" and win-win situation. 


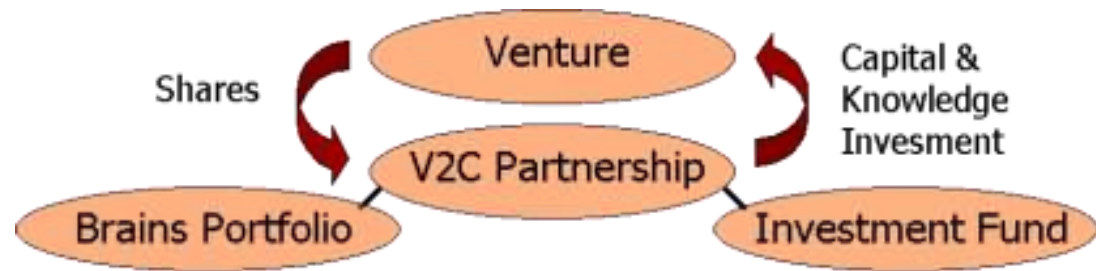

Figure 11. Outlining the Business Model of Optimal V2C Operative

As a summary, the optimal V2C operative should be able to make both capital and knowledge investments to the target venture, to accelerate the initial growth of the company. Both the people working with the company and the V2C player itself should be tied to the target with vested interest. This commitment could best be done in the form of equity stake, releasing the venture from the burden of having to pay for business development services and thus freeing the funds to be targeted to other pro-active activities such as product development, organizational development, sales and marketing. And finally, the partners of this delineated V2C player would have the ambition, entrepreneurship and team spirit needed to work successfully with their target companies, which would - in many ways - resemble their own partnership.

It is not the purpose of this paper to reach decisive conclusions about preferred methods of V2C work, or to build a complete model and taxonomy for the V2C players. Rather, the aim is to open up discussion and pave way to future research on the issue. Before reaching for any conclusive new model there are still many questions to be addressed: What things have changed during the existence of the traditional V2C players? What do these changes require from V2C players? What are the most prominent success factors of $\mathrm{V} 2 \mathrm{C}$ players for themselves and their target ventures? And ultimately: What would the winning V2C business model look like?

\section{References}

Aernoudt, R. (2002). Incubators - tool for entrepreneurship? European Academy of Management EURAM, Stockholm, 9th-11th May 2002.

Bygrave, W. D. and Timmons, J. A. (1992). Venture capital at the crossroads. Boston, MA: Harvard Business School Press.

Coveney, P. and Moore, K. (1998). Business angels: Securing start up finance. Chichester: John Wiley \& Sons.

Erikson, T. and Sørheim, R. (2002). 'Technology angels' and other informal investors. European Academy of Management EURAM, Stockholm, 9th-11th May 2002.

Gaston, R. (1989). Finding Private Venture Capital for Your Firm: A Complete Guide. New York, NY: John Wiley \& Sons.

Jungman, H., Okkonen, J., Rasila, T., Seppä. M., Hannula, M. (2002). Use of Performance Measurement in V2C Activity. International Business \& Economics Research Conference, Las Vegas, 7th-11th October 2002.

Komisar, R. (2001). The Monk and the Riddle. Boston, MA: Harvard Business School Press.

Mason, C. and Harrison, R. (2000). Investing in technology ventures: what do business angels look for at the initial screening stage. In: Reynolds, P D, Autio, E, Brush, C G, Bygrave, W D, Manigart, S, Sapienza, H and Shaver, K G (eds.). Frontiers of Entrepreneurship Research. Babson Park, MA: Babson College.

Mason, C. and Harrison, R. (2001). Investment readiness: a critique of government proposals to increase the demand for venture capital. Regional Studies, 35 . 
Mason, C. and Harrison, R (2002). Addressing Demand Side Constraints in the Informal Venture Capital Market: The Example of LINC Scotland's 'Trial Marriage'. European Academy of Management EURAM, Stockholm, 9th11 th May 2002.

Rasila, T., Seppä. M., Hannula, M. (2002). V2C or Venture-To-Capital - New Model for Crossing the Chasm Between Start-Up Ventures and Venture Capital. European Academy of Management EURAM, Stockholm, 9th-11th May 2002.

Seppä, M. (2000). Strategy Logic of the Venture Capitalist: Understanding venture capitalism - the business within by exploring linkages between ownership and strategy of venture capital companies, over time, in America and Europe. Jyväskylä Studies of Business and Economics, 3. Jyväskylä: University of Jyväskylä (diss.).

Seppä, M. (2002). The Concept of a Knowledge Fund: Proposition for a Structural Solution for the Emerging V2C Industry and the Business of a Venture Knowledgist? e-Business Research Forum eBRF2002, Tampere, 14th-16 ${ }^{\text {th }}$ November 2002.

Sørheim, R. and Landström, H. (2001). Informal investors - A Categorization, with policy implications. Entrepreneurship \& Regional Development. 13.

Interviews:

Source Code Finland, Timo Annala. 11.11.2002

eAccelerator, Pekka Jussila. 11.11.2002 and 19.12.2002

Venture Stables (Yritystallit), Juha Kiljunen. 11.11.2002 